\title{
LOCALIZAÇÃO ECONOMICAMENTE ÓTIMA DAS NOVAS AGROINDÚSTRIAS DE ABATE E PROCESSAMENTO DE AVES E SUÍNOS NO BRASIL ${ }^{1}$
}

\author{
Wendel Sandro de Paula Andrade ${ }^{2}$ \\ Marília Fernandes Maciel Gomes ${ }^{3}$ \\ Heleno do Nascimento Santos ${ }^{4}$ \\ João Eustáquio de Limas
}

Resumo - Este estudo objetivou determinar a localização economicamente ótima de novas agroindústrias de abate e processamento de aves e suínos no Brasil, considerando a minimização dos custos de transporte e aquisição de milho e farelo de soja, e o custo de transporte das carnes. Como referencial teórico, utilizou-se a teoria da localização, na qual se encontra a teoria weberiana da localização industrial, empregada com maior intensidade, e, como procedimento analítico, o modelo de redes capacitadas. O principal resultado foi a indicação de Cândido Mota, SP, para sediar uma agroindústria, decorrente, principalmente, da pouca distância entre esse município e os pólos de oferta de milho e a sua proximidade com importantes regiões consumidoras de carne e com os principais portos marítimos. Para duas plantas, os resultados indicaram Cristalina, GO, e Mafra, SC; para três, as duas cidades anteriormente citadas, com inclusão de Cândido Mota, SP; e para quatro, insere-se Lucas do Rio Verde, MT. Observou-se, ainda, que o custo médio mínimo de atendimento da demanda de carne, considerando o consumo interno brasileiro e as exportações, foi resultante da abertura de quatro unidades agroindustriais. Essa queda no custo foi decorrente da redução na distância percorrida pela carne até os mercados consumidores.

Palavras-chave: Localização, custos de transporte, agroindústria, aves e suínos.

${ }^{1}$ Recebido em: 08/05/2007 Aceito em: 20/09/2007

${ }^{2}$ Professor da Faculdade Ubaense Governador Ozanam Coelho - FAGOC. E-mail: wendelandrade@ hotmail.com.

${ }^{3}$ Professora do Departamento de Economia Rural da UFV. E-mail: mfmgomes@ufv.br

${ }^{4}$ Professor do Departamento de Informática da UFV. E-mail: hns@ dpi.ufv.br

${ }^{5}$ Professor do Departamento de Economia Rural da UFV. E-mail: jelima@ufv.br 


\section{Introdução}

As cadeias agroindustriais de aves e suínos têm-se caracterizado por crescente dinamismo, em razão das mudanças nas características dos produtos, da inserção no mercado internacional, dos ganhos tecnológicos e das sensíveis alterações nas escalas de operações. Essas cadeias, além da importância econômica e da quantidade de proteína em volume de produção, têm desempenhado relevante papel na geração de emprego e renda (Gomes, 2002).

A avicultura foi responsável, em 2002, por cerca de 2,5\% do PIB, pela geração de mais de 3 milhões de empregos em nível nacional e pelo ganho de US \$ 1,34 bilhão em divisas, oriundas das exportações (Poroger e Bianchi, 2004). Em 2005, foram produzidos 9,348 milhões de toneladas de carne de frango, das quais se exportaram 2,76 milhões de toneladas. A produção, nesse ano, concentrou-se nos estados das regiões Sul e Sudeste do país, responsáveis por, aproximadamente, 54 e 26,4\% da produção nacional, respectivamente, sendo o estado do Paraná o maior produtor de frango, com 20,4\% do total nacional (FNP, 2007).

Além do mercado externo, o interno é de extrema importância para o setor avícola, visto que o consumo per capita brasileiro de frango quase triplicou nos últimos 15 anos; em 1990, era de 13,5 kg; em 2001, de 29,5 kg; e em 2005, de 35,7 kg (Gomes, 2002; FNP, 2007).

A participação da suinocultura no PIB agropecuário, em 2002, foi cerca de $10 \%$ e gerou em torno de 1,5 milhão de empregos (Gomes, 2002). No ano de 2005 , a produção nacional foi de 2,70 milhões de toneladas, cerca de $2,82 \%$ da produção mundial. Do total produzido, $77,1 \%$ foram consumidos internamente e $22,9 \%$, destinados à exportação. O efetivo de suínos, nesse mesmo ano, concentrou-se nos estados das regiões Sul, Nordeste e Sudeste, que foram responsáveis por 44, 20 e 17\%, respectivamente, sendo o estado de Santa Catarina responsável pelo maior efetivo, ou seja, 18,5\% do rebanho nacional (FNP, 2007). 
Wendel Sandro de Paula Andrade, Marília Fernandes Maciel Gomes,

Heleno do Nascimento Santos \& João Eustáquio de Lima

Quanto à localização, tem-se observado nova orientação na produção agroindustrial de aves e suínos, da região tradicional (Sul) para a CentroOeste, nos últimos 10 anos. Essa nova orientação não deve ser entendida como uma migração em massa da produção, visto que a produção sulina também cresceu no período. No entanto, de 1997 a 2002, enquanto a região Sul apresentou crescimento de $80 \%$ na produção de carne de frango e de $7 \%$ no efetivo do rebanho suíno, no Centro-Oeste essas taxas foram de 132 e $37 \%$, respectivamente (FNP, 2005a).

Os insumos de maior importância para a produção de aves e suínos são o milho e o farelo de soja. Do total de milho em grão consumido no Brasil no ano de 2000, 72,25\% foi destinado à alimentação de animais; 31,05\%, à avicultura de corte; $5,71 \%$, à avicultura de postura; e $23,60 \%$, à suinocultura (Andrade, 2002). Na categoria animais, a avicultura é responsável pelo consumo de mais de $50 \%$ do milho, o qual representa $60 \%$ da ração balanceada, 40 a $45 \%$ dos custos totais com alimentação, $67 \%$ do custo de produção de animais vivos e $55 \%$ do custo de produção de animais abatidos. O farelo de soja, por sua vez, representa cerca de $20 \%$ das rações balanceadas das aves e contribui com 20 a 25\% para os custos totais de alimentação desses animais (Saboya, 2001).

Segundo Saboya (2001), os produtos agroindustriais, em especial suínos e aves, não estão nem no extremo da máxima dependência de fatores locacionais tradicionais (mão-de-obra, matérias-primas e transporte), nem no outro extremo, como no caso das prestadoras de serviço que se orientam, exclusivamente, para os grandes centros urbanos. Assim, as agroindústrias avícolas e suinícolas são atividades que necessitam de uma abordagem especial, quanto à problemática locacional.

O tema localização agroindustrial, referente às cadeias de aves e de suínos, tem sido abordado por vários autores, dentre os quais, Lopes (1997), que analisou a distribuição de granjas suinícolas no estado de Goiás. O modelo de localização aplicado envolveu uma estrutura de programação inteira-mista, sendo consideradas como variáveis de análise o custo do transporte de grãos (milho e soja) até a granja, o custo do 
transporte de suínos até o abatedouro e o custo de transporte da carcaça suína até o mercado consumidor.

Talamini et al. (1998) analisaram o comportamento das atividades de suinocultura, avicultura e produção de grãos quanto às vantagens das novas regiões do Centro-Oeste. Os determinantes da localização e da estrutura da agroindústria de aves e suínos, selecionados com base na teoria da vantagem competitiva, são custo de produção, processamento e distribuição, potencial para realizar alianças estratégicas, incentivos governamentais, legislação ambiental, capacidade da planta de abate, densidade populacional, aceitação legal e social e infra-estrutura.

Saboya (2001), ao investigar a dinâmica locacional das empresas dos complexos aves e suínos estabelecidas na região Centro-Oeste do Brasil, pesquisou empiricamente os processos de decisão locacional, bem como os fatores-chave na escolha do local produtivo.

Helfand e Rezende (2003) analisaram a vantagem competitiva da região Centro-Oeste, no que se refere à produção de aves e suínos, diante das regiões Sudeste e Sul. Para isso, foram analisados os diferenciais de preços de milho e soja entre os Estados, no período de 1980/95, e estimados os fluxos de comércio de milho, de carne de aves e suína, no mesmo período de análise.

Vasconcelos (2004), por outro lado, analisou os custos de transporte e localização ótima da agroindústria integradora de suínos e aves na região Centro-Oeste brasileira, com o objetivo de indicar locais potenciais para instalações de novas agroindústrias, por meio da minimização dos custos de transporte das matérias-primas (milho em grão) e dos custos de transporte das carnes processadas ou semiprocessadas para os mercados consumidores finais.

Os custos de logística, em especial de transporte, são fatores que limitam o ganho de competitividade das cadeias agroindustriais de aves e suínos 
Wendel Sandro de Paula Andrade, Marília Fernandes Maciel Gomes,

Heleno do Nascimento Santos \& João Eustáquio de Lima

no Brasil, em virtude da elevada participação destes na matriz de custos das empresas. Significativa parcela desses custos envolve relações entre regiões contíguas, para as quais a análise isolada distancia o modelo da realidade. No entanto, não há, na literatura, um estudo que tenha analisado essas cadeias conjuntamente e incluído diversas regiões. Assim, entendese que o conhecimento da logística locacional de mínimo custo das novas agroindústrias de abate e processamento de aves e suínos seja imprescindível para auxiliar os atores do setor privado e governamental nas tomadas de decisões, com vistas em ampliar a competitividade dos distintos setores e propiciar maior geração de emprego e renda para as regiões.

Diante do exposto, o objetivo principal deste trabalho é analisar a logística locacional das agroindústrias em questão, determinando a localização ótima de novas agroindústrias com base na minimização dos custos envolvidos, para o atendimento do consumo em geral e de mercados consumidores específicos.

\section{Referencial teórico}

O referencial teórico deste trabalho está fundamentado nas principais teorias da localização $0^{6}$, que se constituem das teorias de localização agrícola, de Von Thünen, de August Lösch, de Isard-Moses e da Weberiana da Localização Industrial, que foi utilizada mais intensivamente, razão por que se propõe uma sucinta apresentação desta.

6 Maiores informações, ver Ferreira (1975), Leme (1982), Haddad (1989), Clemente (1994), Figueiredo (1998) e Clemente e Higachi (2000). 


\subsection{A Teoria Weberiana da Localização Industrial}

Alfred Weber iniciou seu estudo, quanto ao ponto ótimo de localização, pela análise dos custos de transporte, que tem, nessa teoria, papel crucial na determinação da localização das atividades industriais. Esses custos são uma função do peso físico do produto e da distância a ser percorrida. Pelo triângulo locacional representado na Figura 1, esse autor determinou o ponto de custo mínimo de transporte e utilizou, em sua análise, um caso simplificado, em que se tem um ponto comum de consumo e dois depósitos de matérias-primas (Haddad, 1989).

De acordo com essa teoria, tem-se que $\mathrm{C}$ é ponto de consumo; $\mathrm{M}_{1}$, fonte de matérias-primas $1 ; \mathrm{M}_{2}$, fonte de matérias-primas $2 ; \mathrm{P}$, ponto de custo total e de transporte mínimo; $\mathrm{d}_{1}, \mathrm{~d}_{2}$ e $\mathrm{d}_{3}$, distâncias respectivas entre os três pontos; e x, y e z, vetores que representam as forças de atração das fontes de matérias-primas 1 e 2 e do mercado C.

Os pontos C, M1 e M2 criam forças de atração nas respectivas direções, proporcionais ao peso por unidade do produto final a ser transportado para o local de produção e do local de produção para o mercado. O ponto no qual o total de toneladas/quilômetro, referente ao transporte de matérias-primas para o local de produção e do produto final para o mercado, é mínimo denomina-se localização de custo mínimo.

Via de regra, os custos de transporte são resultantes de tarifas nãoproporcionais, ou seja, que se reduzem, em valor unitário, com o aumento da distância a ser percorrida. 


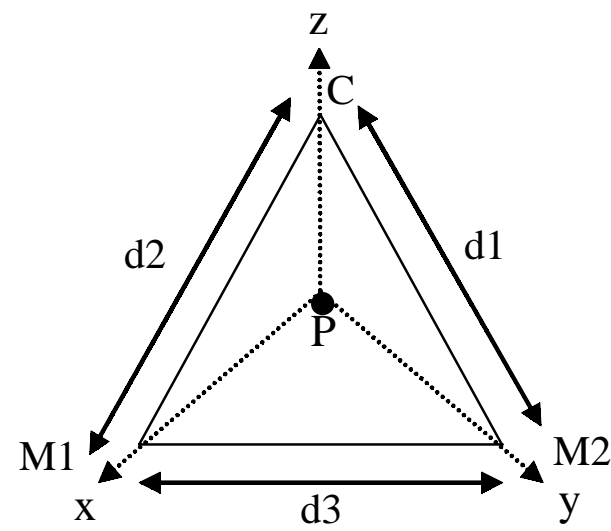

Figura 1 - Triângulo locacional de Weber.

Fonte: Haddad, 1989.

Cosenza e Nascimento (1975), no entanto, ressaltaram que há outros fatores importantes para a localização de uma indústria, além do já considerado custo de transporte. Segundo esses autores, é necessário definir os critérios que permitam abranger maior número de características regionais, relevantes à decisão locacional, e ponderar essas características com base em uma ordem de importância previamente estabelecida.

Segundo eles, devem ser considerados fatores como distribuição da população no território, com vistas na facilidade do recrutamento de mãode-obra; atual distribuição da atividade industrial no território em estudo, considerando-se como unidade de medida o número de pessoas ocupadas nas indústrias; características topográficas da região; existência de um sistema de infra-estrutura apropriado, como rodovias, ferrovias, hidrovias, portos, fornecimento de energia elétrica e outros; e consideração dos usos alternativos do território, para evitar que a atividade industrial entre em conflito com quaisquer outras formas de uso territorial, atual ou potencial. Entretanto, este trabalho considerou, unicamente, os custos de transporte de milho, farelo de soja e carnes, e os custos de aquisição dos referidos insumos, por entender que são eles os principais fatores 
econômicos que influenciam a decisão locacional da agroindústria em estudo.

\section{Metodologia}

3.1. Modelo de redes capacitadas aplicado ao problema de localização

O instrumental analítico utilizado neste trabalho, para determinar as localizações economicamente ótimas, foi o de redes capacitadas, em que o problema de localização é resolvido, matematicamente, pelo uso de Programação Inteira, por meio de uma variação do modelo de transporte original. $\mathrm{O}$ modelo utilizado na solução de problemas de localização discreta de instalações, apresentado por Santos (1990) e modificado para os propósitos deste trabalho, é o que segue:

Minimizar: $Z=$

$$
\sum_{i=1}^{m} \sum_{j=1}^{n}\left(C_{i j}+P_{i}\right) X_{i j}+\sum_{e=1}^{w} \sum_{j=1}^{n}\left(C_{e j}+P_{e}\right) X_{e j}+\sum_{j=1}^{n} \sum_{d=1}^{t} C_{j d} X_{j d}+\sum_{i=1}^{m} F_{i} Y_{i}
$$

sujeito a:

$$
\begin{aligned}
& \sum_{d=1}^{t} D_{d} X_{j d} \leq Q_{j} Y_{j}, \quad i=1,2, \ldots, \mathrm{m}, \\
& \sum_{j=1}^{n} X_{j d}=1, \quad d=1,2, \ldots, \mathrm{t},
\end{aligned}
$$


Wendel Sandro de Paula Andrade, Marília Fernandes Maciel Gomes,

Heleno do Nascimento Santos \& João Eustáquio de Lima

$$
\begin{aligned}
& \sum_{i=1}^{m} X_{i j}=q_{j} Y_{j}, \quad \mathrm{j}=1,2, \ldots, \mathrm{n}, \\
& \sum_{e=1}^{w} X_{e j}=q_{j}^{*} Y_{j}, \quad \mathrm{j}=1,2, \ldots, \mathrm{n}, \\
& \sum_{j=1}^{n} X_{i j}=q_{i}, \quad \mathrm{i}=1,2, \ldots, \mathrm{m}, \\
& \sum_{j=1}^{n} X_{e j}=q_{e}, \quad \mathrm{e}=1,2, \ldots, \mathrm{w}, \\
& 0 \leq X_{i j} \leq 1, \text { para todo } i, j, \\
& 0 \leq X_{e j} \leq 1, \text { para todo } e, j, \\
& \mathrm{Y}_{\mathrm{i}} \in\{0,1\}, \text { para todo } \mathrm{i}=1,2, \ldots, \mathrm{m},
\end{aligned}
$$

em que $\mathrm{Z}$ é custo total; i indexa os locais que representam os pólos produtores de milho; j indexa os locais que representam os pólos candidatos a receber a agroindústria; d indexa os locais que representam os pólos consumidores de carnes de aves e de suínos; $\mathrm{D}_{\mathrm{d}}$, quantidade demandada pelo cliente $\mathrm{d} ; \mathrm{C}_{\mathrm{ij}}$, custo unitário de transporte de milho entre os pontos $\mathrm{i}$ e j, sendo $\mathrm{C}_{\mathrm{ij}} 0 ; \mathrm{C}_{\mathrm{jd}}$, custo unitário de transporte de carnes entre os pontos j e d, sendo $\mathrm{C}_{\mathrm{jd}} \geq 0 ; \mathrm{C}_{\mathrm{ej}}$, custo unitário de transporte do farelo de soja entre os pontos $e$ e j, sendo $\mathrm{C}_{\mathrm{ej}} \geq 0 ; \mathrm{P}_{\mathrm{i}}$, preço unitário de aquisição do milho na região de oferta $\mathrm{i} ; \mathrm{P}_{\mathrm{e}}$, preço unitário de aquisição do farelo de soja na esmagadora $e ; \mathrm{X}_{\mathrm{ij},}$ fração da demanda de $\mathrm{j}$, atendida pela região produtora $\mathrm{i}$, sendo $0 \leq \mathrm{X}_{\mathrm{ij}} \leq 1 ; \mathrm{X}_{\mathrm{ej}}$, fração da quantidade demandada de $\mathrm{j}$, atendida pela esmagadora $e$, sendo $0 \leq \mathrm{X}_{\mathrm{ej}} \leq 1 ; \mathrm{X}_{\mathrm{jd}}$, fração da quantidade 
demandada de d, atendida pela instalação $\mathrm{j}$, sendo $0 \leq \mathrm{X}_{\mathrm{jd}} \leq 1 ; \mathrm{Q}_{\mathrm{j}}$, capacidade de oferta de carne dos pólos candidatos $\mathrm{j} ; \mathrm{q}_{\mathrm{i}}$, capacidade de oferta de milho dos pólos produtores $\mathrm{i} ; \mathrm{q}_{\mathrm{e}}$ capacidade de oferta de farelo de soja das esmagadoras $e ; \mathrm{q}_{\mathrm{j}}$, demanda de milho pelo pólo candidato $\mathrm{j}$; $\mathrm{q}_{\mathrm{j}}{ }^{*}$, demanda de farelo de soja pelo pólo candidato $\mathrm{j} ; \mathrm{F}_{\mathrm{j}}$, custo fixo associado à abertura da instalação j; e $\mathrm{Y}_{\mathrm{j}}$, variável binária de valor 1, se a instalação j for efetivada, e de valor 0 , caso contrário.

A função objetivo (1) é formada por quatro parcelas, sendo a primeira constituída pelos custos variáveis de captação do milho; a segunda, pelos custos variáveis de captação do farelo de soja; a terceira, pelos custos variáveis de distribuição das carnes; e a quarta, pelos custos fixos. A restrição (2) assegura que a demanda de carnes só será atendida por novas indústrias abertas; a (3), que a demanda de carne por todos os clientes $^{7}$ seja satisfeita; a (4), que o milho proveniente das regiões produtoras deverá suprir, exatamente, a demanda pelo pólo candidato, se este for aberto; a (5), que o farelo de soja proveniente das esmagadoras deverá suprir, exatamente, a demanda pelo pólo candidato, se este for aberto; a (6), que a quantidade de milho proveniente dos pólos produtores para os pólos candidatos deverá ser, no máximo, a capacidade de oferta do pólo produtor; a (7), que a quantidade de farelo de soja, proveniente das esmagadoras para os pólos candidatos, deverá ser, no máximo, a capacidade de oferta da esmagadora; a (8) busca limitar a variável $\mathrm{X}_{\mathrm{i}}$, que pode variar de um não-atendimento $\left(X_{\mathrm{ij}}=0\right)$ a um atendimento total $\left(X_{\mathrm{ij}}=1\right)$, pelo pólo i, da quantidade demandada pela instalação j; a (9) busca limitar a variável $X_{\mathrm{ej}}$, que pode variar de um não-atendimento $\left(X_{\mathrm{e} j}\right.$ $=0)$ a um atendimento total $\left(\mathrm{X}_{\mathrm{ej}}=1\right)$, pela esmagadora $e$, da quantidade demandada da instalação j; e por fim, a restrição (10), que contém uma variável binária, o que torna possível somente que as instalações nos locais candidatos sejam abertas, ou não.

Alguns pressupostos nos quais o modelo de redes capacitadas está fundamentado devem ser ressaltados, a saber: a) Estrutura de mercado de competição perfeita; b) Homogeneidade do produto considerado; c)

Mercado interno e externo. 
Wendel Sandro de Paula Andrade, Marília Fernandes Maciel Gomes,

Heleno do Nascimento Santos \& João Eustáquio de Lima

Conhecimento das quantidades ofertadas e demandadas em cada região; e d) Custo de transporte, independente da quantidade transportada (Vieira, 1992).

Neste estudo será aplicado o modelo de redes capacitadas sem restrição de fonte única, em que cada instalação $j$ poderá ter qualquer fração de demanda de milho atendida pelo pólo $i$ e de demanda de farelo de soja atendida pela esmagadora $e$, inclusive os casos extremos do nãoatendimento e do atendimento integral de suas demandas pelos referidos pólos e esmagadoras.

\subsection{Fonte e descrição dos dados}

Na seleção dos pólos produtores de milho e, conseqüentemente, dos candidatos à instalação de uma agroindústria utilizaram-se dados da produção de milho e do efetivo dos rebanhos de aves e suínos, no ano de 2002, do Instituto Brasileiro de Geografia e Estatística - IBGE (2004). Como tamanho de planta de uma agroindústria a ser instalada usou-se o porte da presente no Projeto Buriti da Perdigão, na região Centro-Oeste, na cidade de Rio Verde, GO, a qual apresentava capacidade diária de abate de 281.000 aves e 3.500 suínos (Perdigão, 2004). Essas informações permitiram calcular a oferta e a demanda de milho regionais, assim como a demanda de milho por parte da agroindústria, verificados os pólos que possuíam maior excedente de milho, a uma distância rodoviária máxima de $400 \mathrm{~km}$, utilizada com base em Vasconcelos (2004).

Como pólos produtores de farelo de soja foram consideradas as localizações das empresas associadas à Associação Brasileira das Indústrias de Óleos Vegetais - ABIOVE, responsáveis por $80 \%$ do esmagamento de soja no Brasil (ABIOVE, 2004).

O conjunto dos pólos de demanda de carnes considerados no modelo é composto por todos os estados brasileiros, inclusive o Distrito Federal, referentes ao consumo interno e por portos marítimos de Itajaí, SC, 
Paranaguá, PR, e Santos, SP, que respondem por $89 \%$ das exportações brasileiras de carnes.

As distâncias utilizadas no modelo basearam-se no Guia Quatro Rodas (2004), no qual foi utilizada a opção "rota mais rápida" em vez da "rota mais curta", em razão de a segunda, por diversas vezes, indicar rotas com estradas sem pavimentação, o que seria problema para o tráfego de veículos pesados.

Os custos unitários de transporte foram obtidos do Sistema de Informação de Frete de Cargas Agrícolas (SIFRECA/ESALQ-USP), no ano de 2002. Para o transporte de milho e farelo de soja foram considerados os valores de frete do transporte em carretas com capacidade de carga de $27 \mathrm{t}$ e, para o transporte de carnes, o frete em carretas frigorificadas com 21,5 t de capacidade de carga. Os valores estão apresentados na Tabela 1.

Tabela 1 - Custo de transporte de milho, de farelo de soja e de carnes, com base na distância percorrida

\begin{tabular}{cccc}
\hline \multicolumn{2}{c}{ Milho e farelo de soja } & \multicolumn{2}{c}{ Carnes } \\
\hline Distância & Frete & Distância & Frete \\
\hline (km) & $(\mathbf{R} \$ \mathbf{t} / \mathbf{k m})$ & $(\mathbf{k m})$ & $(\mathbf{R} \$ / \mathbf{t} / \mathbf{k m})$ \\
\hline 0 a 400 & 0,0990 & 0 a 600 & 0,1497 \\
\hline 401 a 800 & 0,0700 & 601 a 1.600 & 0,1292 \\
\hline 801 a 1.200 & 0,0632 & $>1.600$ & 0,0938 \\
\hline > 1.200 & 0,0526 & & \\
\hline
\end{tabular}

Fonte: Elaborado pelos autores e adaptado de SIFRECA, 2004.

A série mensal de preços de milho, no ano de 2004, foi obtida da Fundação Getúlio Vargas - FGV (2004) e corrigida para dezembro de 2002, com base no IGP-DI da FGV (Fundação Getúlio Vargas). De posse dos preços reais, obteve-se a média anual de cada estado, como segue: Mato Grosso, R \$240,19/t; Mato Grosso do Sul, R \$263,42/t; Paraná, R \$272,02/t; Goiás, R\$286,42/t; Minas Gerais, R\$297,67/t; Santa Catarina, R\$299,93/t; e São Paulo, R\$306,69/t. 
Wendel Sandro de Paula Andrade, Marília Fernandes Maciel Gomes,

Heleno do Nascimento Santos \& João Eustáquio de Lima

Os preços diários do farelo de soja, nas 13 praças diferentes, foram obtidos do FNP (2005), em R $\$ / t$, os quais foram agrupados em valores médios anuais por estado, sendo posteriormente corrigidos para dezembro de 2002, de acordo com o IGP-DI da FGV, descritos a seguir: Mato Grosso, R \$ 573,27/t; Minas Gerais, R \$ 593,85/t; Goiás, R \$ 594,59/t; Bahia, R \$ 600,88; São Paulo, R \$ 606,54/t; Paraná, R\$ 617,45/t; Mato Grosso do Sul, R\$ 627,73/t; Santa Catarina, R\$ 635,97/t; e Rio Grande do Sul, R\$ 648,91 .

Neste estudo considerou-se como custo de abertura para instalação de uma agroindústria o valor de $\mathrm{R} \$ 412$ milhões, que foi extraído de Perdigão (2004) e refere-se ao investimento destinado à implantação do Projeto Buriti. Ressalta-se que esse valor foi considerado constante em todos os pólos candidatos à instalação de uma agroindústria.

\section{Resultados e discussão}

A partir das informações sobre oferta de milho, verificou-se que nem todos os pólos pré-selecionados tinham capacidade para suprir tal agroindústria com esse insumo. Assim, decidiu-se que os pólos candidatos à instalação de uma agroindústria do porte já descrito anteriormente e que iriam entrar no modelo de localização seriam: Unaí, MG; Cândido Mota, SP; Mafra, SC; Lucas do Rio Verde, MT; Chapadão do Sul, MS; e Cristalina, GO. As informações sobre esses pólos são apresentadas na Tabela 2. 
Tabela 2 - Produção de milho, demanda de milho total, excedente de milho na microrregião e excedente de milho até $400 \mathrm{~km}$ de distância, em 2002, nos pólos pré-selecionados, em toneladas

\begin{tabular}{lrrrr}
\hline \multicolumn{1}{c}{ Pólo } & Produção & Demanda & $\begin{array}{c}\text { Excedente na } \\
\text { microrregião }\end{array}$ & $\begin{array}{c}\text { Excedente } \\
\text { até 400 km }\end{array}$ \\
\hline Unaí, MG & 417.090 & 33.738 & 383.352 & 1.183 .589 \\
\hline Cândido Mota, SP & 304.175 & 39.438 & 264.737 & 979.506 \\
\hline Mafra, SC & 462.230 & 168.442 & 293.788 & 1.273 .518 \\
\hline Lucas do Rio Verde, MT & 959.853 & 214.791 & 745.062 & 559.456 \\
\hline Chapadão do Sul, MS & 243.510 & 34.545 & 208.965 & 717.235 \\
\hline Cristalina, GO & 615.359 & 130.123 & 485.236 & 1.510 .122 \\
\hline
\end{tabular}

Fonte: IBGE (2004) e dados da pesquisa.

Observadas as formas como as variáveis devem ser interpretadas e tendo em vista as restrições adotadas, a melhor interpretação dos resultados do modelo, quanto à abertura de uma única planta, é a que segue. De acordo com a solução do modelo inicial, a cidade de Cândido Mota, SP, foi a que apresentou o menor valor para a função objetivo, sendo tal resultado o efeito das características que fazem desta a melhor localização em relação às demais. Primeiramente, pode-se considerar a proximidade dessa região com o estado do Paraná, maior produtor de milho do Brasil e provedor de todo o milho destinado à unidade de Cândido Mota, já que seu produto foi o terceiro mais barato do país no ano de 2002. O farelo de soja foi adquirido no estado de São Paulo, que, apesar de não estar entre os de menor preço do país, apresentou o menor custo de transporte, dentre as demais opções locacionais, produto que pode ser todo proveniente de Ourinhos, SP, que está apenas a $70 \mathrm{~km}$ de distância do pólo escolhido. Outro importante fator que contribuiu para que esse pólo fosse indicado, em detrimento de outro pertencente à região CentroOeste, além do custo de reunião dos insumos, foi a maior proximidade do mercado consumidor. O fato é que $72 \%$ da demanda em questão está localizada nas regiões Sul e Sudeste, sendo 35\% no Sudeste, $17 \%$ no Sul e $20 \%$ correspondente à demanda externa, escoada por dois portos do Sul e um do Sudeste. 
Wendel Sandro de Paula Andrade, Marília Fernandes Maciel Gomes,

Heleno do Nascimento Santos \& João Eustáquio de Lima

Ao modificar o modelo original, inserindo a restrição de que duas plantas agroindustriais, de mesmo porte, deveriam ser abertas, os resultados não mais apontaram o estado de São Paulo, o que indica que essas unidades deveriam ser implantadas em Cristalina, GO, e em Mafra, SC. Essas são opções de localização que, sem dúvida, têm o intuito de dividir o mercado consumidor de carnes nos pólos que lhes proverão esses produtos.

Ao inserir a restrição de que três plantas deveriam ser abertas, a resposta foi a inserção de Cândido Mota na opção descrita anteriormente (duas plantas), em que essa se associa aos pólos já definidos, quais sejam, Cristalina, GO, e Mafra, SC. No entanto, ao inserir no modelo a obrigatoriedade da abertura de quatro plantas, inclui-se nesse grupo o pólo de Lucas do Rio Verde, MT, e, com cinco plantas em operação, insere-se o pólo de Chapadão do Sul, MS.

Em virtude do aumento no número de instalações abertas teve-se um crescimento no valor da função objetivo, ou seja, no custo total associado ao modelo, o que resultou no aumento dos custos fixos e variáveis. Entretanto, houve redução no custo de atendimento unitário da demanda, que é um custo variável, à medida que outras instalações iam sendo abertas até o número de quatro plantas, ocorrendo aumento no custo de atendimento unitário com a abertura da quinta planta, em Chapadão do Sul. Essa inferência foi possível, dada a observação de que o valor da função objetivo, até a abertura da quarta unidade, teve aumento menos que proporcional ao da demanda atendida ou, ainda, ao número de instalações abertas.

Dois outros modelos de localização foram estruturados; um objetivou atender somente à demanda interna da região Sul e outro, somente à demanda externa, via portos de Itajaí, Paranaguá e Santos. Verificou-se que a escolha da cidade de Mafra, SC, foi resultante desses dois modelos de localização, sendo importante enfatizar que o Porto de Itajaí, em Santa Catarina, teve maior importância para as exportações brasileiras de carnes. 
No caso de uma planta que visasse ao atendimento somente do mercado interno, a localização indicada seria a cidade de Cristalina, no estado de Goiás, que apresentou excedente de milho, na própria microrregião, mais que suficiente para atender a toda demanda de uma agroindústria, o que implica, segundo pressupostos deste estudo, custo de transporte de milho igual a zero. Quanto ao preço FOB do milho, o estado de Goiás apresentou valor quase $7 \%$ inferior ao de São Paulo, o que veio a colaborar para que esse novo resultado fosse preferível à indicação do Sudeste. No que concerne ainda aos insumos, o farelo de soja, em Goiás, apresentou preço $2 \%$ abaixo do praticado em São Paulo, sendo seu custo de transporte igual ao das duas regiões. Em face desses resultados, conclui-se que, com redução na demanda atribuída ao Sul e Sudeste do país, por meio do não-atendimento das exportações, visto que os portos considerados no modelo estão localizados nessas duas regiões, o peso do custo do transporte de carnes nessas regiões seria menor, o que implicaria interiorização regional dos investimentos na agroindústria, conduzida pelo menor custo de reunião das matérias-primas.

Ao analisar a possibilidade de atendimento da demanda de carnes somente na região Nordeste do Brasil, verifica-se que o pólo de Cristalina foi escolhido por apresentar o menor custo total, além de ser o de maior proximidade com o Nordeste, o que permite custos de transporte de carne reduzidos.

Em se tratando do atendimento das regiões Norte e, ou, Centro-Oeste, as quais, em conjunto, apresentavam demanda de carne inferior à das regiões Nordeste e Sul, isoladamente, o pólo escolhido foi o de Lucas do Rio Verde, MT, dada a grande proximidade dessa cidade aos mercados consumidores referenciados e dado o fato de esta apresentar menor preço dos insumos do país.

$\mathrm{Na}$ seqüência de modelos de atendimento às regiões restritas, tem-se o pólo de Cândido Mota, SP, escolhido para sediar a produção de carnes direcionada ao suprimento da região Sudeste. Esse resultado baseou-se nos mesmos fatores que tornaram esse pólo o de menor custo total para 
Wendel Sandro de Paula Andrade, Marília Fernandes Maciel Gomes,

Heleno do Nascimento Santos \& João Eustáquio de Lima

o atendimento de todo o país e no fato de ter grande proximidade com os principais centros consumidores de carne e pólos ofertantes de milho e farelo de soja.

Além das indicações de localização dos modelos, podem-se extrair desses resultados algumas informações sobre a participação dos custos do milho, farelo de soja e carnes nos custos variáveis e nos custos totais associados à agroindústria. Considerando a localização principal, que é em Cândido Mota, SP, foi elaborada a Tabela 3, que ilustra a participação dos custos dos fatores milho e farelo de soja e das carnes nos custos variáveis e totais.

Verifica-se, nessa tabela, que o custo da compra do milho é responsável por quase metade dos custos variáveis aqui considerados, seguido do custo de aquisição do farelo de soja, que responde por $34 \%$ dos custos variáveis, e do custo de transportes, que representa os demais 17,48\%. Destacam-se, ainda, os custos de transporte de carnes, que representam $81 \%$ dos custos totais com transportes.

O alto custo de compra e transporte de milho é reflexo da elevada participação desse insumo no processo produtivo, visto que este item tem maior participação nas rações formuladas tanto para aves quanto para suínos. Quanto à elevada soma destinada ao transporte de carnes em relação ao transporte dos insumos, pode-se dizer que esse resultado é conseqüência de duas situações; a dispersão da demanda de carnes e o valor unitário do frete para cargas frigorificadas. A primeira delas decorre do fato de ter se optado, neste modelo, pelo atendimento de todas as regiões do país, visto que a produção de uma planta agroindustrial foi dividida para todos os estados, de modo proporcional à participação do estado na demanda brasileira de carnes. Como uma só planta atendia a todo o país, as distâncias de transporte eram relativamente grandes. Já no que se refere ao frete, tem-se que o seu valor em reais por quilômetro é, em média, 74\% maior que o de transporte de grãos, o que pode ser explicado pela menor tonelagem por viagem, pelo maior valor dos ativos fixos envolvidos e pelo maior consumo de combustível, em razão do equipamento de refrigeração. 
Tabela 3 - Participação dos custos do milho, do farelo de soja e das carnes nos custos variáveis e nos custos totais, considerandose Cândido Mota, SP, como a cidade-pólo

\begin{tabular}{lrrr}
\hline \multicolumn{1}{c}{ Itens de custo } & \multicolumn{1}{c}{ Valor (R\$) } & CV (\%) & CT (\%) \\
\hline Preço FOB do milho & $122.544 .115,10$ & 48,52 & 18,44 \\
\hline Preço FOB do farelo de soja & $85.862 .973,02$ & 34,00 & 12,92 \\
\hline Custo de transporte do milho & $7.452 .658,90$ & 2,95 & 1,12 \\
\hline Custo de transporte do farelo de soja & $977.026,98$ & 0,39 & 0,15 \\
\hline Custo de transporte das carnes & $35.713 .000,00$ & 14,14 & 5,37 \\
\hline Custo variável total & $252.549 .774,00$ & 100,00 & 38,00 \\
\hline Custo fixo total & $412.000 .000,00$ & & 62,00 \\
\hline Custo total & $664.549 .774,00$ & & 100,00 \\
\hline
\end{tabular}

Fonte: Dados da pesquisa.

\section{Conclusões}

No que se refere à possibilidade de abertura de uma única agroindústria, tem-se como município-pólo a cidade de Cândido Mota, em São Paulo, dado que foi o local que apresentou menor custo total, considerando tanto o atendimento da demandas interna quanto da externa. A indicação de um pólo na região Sudeste, em detrimento dos pólos candidatos do Centro-Oeste, se deve aos custos dos insumos e de distribuição das carnes. Os menores preços do milho e do farelo de soja praticados no Centro-Oeste e, em especial, no estado de Mato Grosso não foram suficientes para compensar os custos mais elevados de distribuição das carnes, decorrente de frete mais elevado para cargas frigorificadas e de concentração da demanda, que é alta no Sudeste e não no Centro-Oeste. Ao excluir a demanda de exportação, atualmente concentrada no Sul e no Sudeste, a melhor localização foi alterada de Cândido Mota, SP, para Cristalina, GO.

Na possibilidade de abertura de mais de uma planta, verifica-se que haveria redução no custo médio de atendimento em até quatro plantas, que foram definidas para as cidades de Mafra, SC, Cândido Mota, SP, Lucas do 
Wendel Sandro de Paula Andrade, Marília Fernandes Maciel Gomes,

Heleno do Nascimento Santos \& João Eustáquio de Lima

Rio Verde, MT, e Cristalina, GO, em face do menor custo por quilograma de carne enviada ao mercado consumidor. Entende-se, assim, que esse resultado é decorrente da maior proximidade entre agroindústria e mercado consumidor. Tais resultados apontam uma decisão locacional que, claramente, considera o custo de atendimento à demanda de carnes, o preço do milho e a proximidade deste com as agroindústrias, fatores importantes, mas não suficientes, para determinar a localização da agroindústria, uma vez que, no ano de 2002, o milho paranaense apresentou um preço 5,30\% mais baixo que o de Goiás, 3,16\% maior que o de Mato Grosso do Sul e 11,70\% maior que o de Mato Grosso.

Para atendimento de mercados consumidores específicos, os pólos escolhidos foram as cidades de Cristalina, GO, para atender ao mercado consumidor do Nordeste, como também ao mercado consumidor interno; Mafra, SC, para atender ao mercado externo e, ou, à região Sul; Cândido Mota, SP, à região Sudeste; e Lucas do Rio Verde, MT, à região Norte e ao Centro-Oeste.

No que se refere aos custos mais significativos para abertura de uma única planta, sendo esta em Cândido Mota, SP, verifica-se que as variáveis que influenciaram fortemente essa decisão foram os custos de aquisição e transporte de milho, que corresponderam a mais da metade dos custos variáveis incluídos no modelo. Essa elevada participação do milho nos custos locacionais ocorreu em razão de este ser o insumo mais importante para a produção de aves e suínos. Observou-se, ainda, elevada participação do custo de transporte das carnes, o que se deve às grandes distâncias percorridas até o mercado consumidor e à elevada tarifa de transporte para produtos frigorificados.

Em síntese, conclui-se que a variável de maior influência na definição locacional das agroindústrias de aves e suínos foi o preço do milho, seguido do preço do farelo de soja e dos custos de transportes envolvidos. 


\section{Referências}

ANDRADE, W.S.P. Estudo prospectivo das demandas de milho e sorgo. Viçosa, MG: UFV, 2002. 124 f. Dissertação (Mestrado em Economia Aplicada) - Universidade Federal de Viçosa, Viçosa.

ASSOCIAÇÃO BRASILEIRA DAS INDÚSTRIAS DE ÓLEOS VEGETAIS - ABIOVE. Abiove. Disponível em: <http:// www.abiove.com.br>. Acesso em: 12 out. 2004.

CLEMENTE, A. Economia regional e urbana. São Paulo: Atlas, 1994. $170 \mathrm{p}$.

CLEMENTE, A.; HIGACHI, H.Y. Economia e desenvolvimento regional. São Paulo: Atlas, 2000. 260 p.

COSENZA, C.A.N.; NASCIMENTO, P.R. Alguns modelos empíricos de localização industrial. Pesquisa e planejamento econômico, v. 5, n. 1, p. 261-72, jun. 1975 .

FERREIRA, C.M.C. A evolução das teorias clássicas da economia espacial: suas contribuições para a análise da concentração das atividades. Belo Horizonte: UFMG/CEDEPLAR, 1975. 318 p. (Monografia extraída da tese apresentada ao concurso para professor titular junto à Faculdade de Ciências Econômicas da UFMG).

FIGUEIREDO, A.T.L. Padrão locacional e especializações regionais da indústria mineira. Belo Horizonte: CEDEPLAR/UFMG, 1998. 145 f. Dissertação (Mestrado em Economia) - Universidade Federal de Minas Gerais, Belo Horizonte.

FNP CONSULTORIA \& AGROINFORMATIVOS. Boletim diário - soja: cotação dos derivados de soja - farelo de soja. boletim n ${ }^{\circ} 146$ a n 388. Adquirido em: <http://www.fnp.com.br〉. Acesso em: 15 jan. 2005. 
Wendel Sandro de Paula Andrade, Marília Fernandes Maciel Gomes,

Heleno do Nascimento Santos \& João Eustáquio de Lima

FNP CONSULTORIA \& COMÉRCIO. Anualpec. São Paulo: Editora Argos Comunicação, 2007.

FUNDAÇÃO GETÚLIO VARGAS - FGV. Preços recebidos pelos produtores de milho. Disponível em: 〈http://fgvdados.fgv.br >. Acesso em: 15 set. 2004.

GOMES, M.F.M. As cadeias agroindustriais de carnes. In: Banco de Desenvolvimento de Minas Gerais (BDMG). In: MINAS GERAIS DO SÉCULO XXI. Belo Horizonte: Rona Editora, 2002. p. 59 - 86 (volume IV: Transformando o desenvolvimento na agropecuária).

GUIA QUATRO RODAS. CD-ROM Rodoviário. 2004.

HADDAD, P.R. (Org.). Economia regional: teorias e métodos de análise. Fortaleza: BNB/ETENE, 1989. 694 p.

INSTITUTO BRASILEIRO DE GEOGRAFIA E ESTATÍSTICA IBGE. Produção Agrícola Municipal e Produção Pecuária Municipal em 2002. Disponível em: 〈http://www.ibge.gov.br〉. Acesso em: 23 nov. 2004.

LEME, R.A. da S. Contribuições à teoria da localização industrial. São Paulo: IPE/USP, 1982. 387 p.

PERDIGÃO. A empresa. Disponível em: < $\underline{\text { http:// }}$ www.perdigao.com.br>. Acesso em:12 jul. 2004.

POROGER, S.; BIANCHI, R. União brasileira dos avicultores aperta cerco contra os nitrofuranos. Disponível em : < $\underline{\mathrm{http}: / /}$ www.spmj.com.brasileira/destaques/dest 07.php>. Acesso em: 07 jun. 2004.

SABOYA, L.V. A dinâmica locacional da avicultura e suinocultura no Centro-Oeste brasileiro. Piracicaba, SP: ESALQ/USP, 2001. 166 f. Dissertação (Mestrado em Economia Aplicada) - Escola Superior de Agricultura Luiz de Queiroz, Piracicaba. 


\begin{abstract}
SANTOS, H.N. Métodos de solução para problemas de localização capacitados com ou sem restrição de fonte única. Rio de Janeiro: UFRJ, 1990. 143 f. Tese (Doutorado em Engenharia da Produção) Universidade Federal do Rio de Janeiro, Rio de Janeiro.
\end{abstract}

SISTEMA DE INFORMAÇÃO DE FRETES E CARGAS AGRÍCOLAS - SIFRECA. Fretes rodoviários. Disponível em: < $\underline{\text { http:/ }}$ /sifreca.esalq.usp.br/>. Acesso em: 30 ago. 2004.

VASCONCELOS, F.M.M. Localização ótima da agroindústria integradora de suínos e aves na Região Centro-Oeste do Brasil. Viçosa, MG: UFV, 2004.109 f. Dissertação (Mestrado em Economia Aplicada) - Universidade Federal de Viçosa, Viçosa.

VIEIRA, W.C. Análise econômica de transporte e armazenagem de arroz no Estado do Maranhão. Porto Alegre, RS: UFRGS, 1992. 125 f. Dissertação (Mestrado em Economia Rural) - Universidade Federal do Rio Grande do Sul, Porto Alegre.

Abstract - The objective of this study is to determine the optimum economically
location of new slaughter and processing plants of poultry and pork in Brazil, considering
the minimization of transportation cost and acquisition of corn and soy bran, and the
transportation cost of meat. The theory of localization was used, as theoretical approach,
reletead to the weberiana theory of the industrial localization, used, with larger intensity.
Network capacited model is used as analytic tool. The main result was the indication of
Cândido Mota, SP, for the set the processing plant, due, mainly, a short distance among
that municipal district and the corn production cluster and its proximity with important
meat consuming areas, and with the main ports. The results indicated: for two plants,
Cristalina, GO, and Mafra, SC; for the three plants, the two cities previously mentioned,
with the inclusion of Cândido Mota, SP, and for four plants, it is insert Lucas do Rio
Verde, MT. It was observed that the minimum medium cost of attendance of meat
demand, considering the brazilian internal consumption and the exports, was resultant
of to opening of four plants that cost decrease was due to reduction in the distance
traveled by the until the consuming markets.

Key words: Localization, transportation cost, meat processing plants, poultry and pork. 